\title{
O Desenvolvimento da Atividade Turística na Cidade de Capitólio (Minas Gerais/Brasil) Baseado nos Atrativos e Opções de Lazer Existentes
}

https://doi.org/10.21814/uminho.ed.48.21

Annaelise Fritz Machado

Escola Superior de Hotelaria e Turismo, Instituto Politécnico do Cávado e do Ave, Barcelos, Portugal https://orcid.org/0000-0003-3849-7350 annaelisefritz@yahoo.com.br

Magno Angelo Kelmer

Universidade de Goiás, Goiás, Brasil https://orcid.org/0000-0003-4905-4889 magnokelmer@gmail.com

Zilpa Helena Lovisi de Abreu

Universidade de Vigo, Vigo, Espanha https://orcid.org/0000-0002-0336-4817 zilpa.abreu@estacio.br

\section{Resumo}

Capitólio, pequena cidade localizada no sudoeste de Minas Gerais, conhecida como "mar de minas", faz parte do Lago de Furnas, área alagada artificialmente nos anos de 1950 para a construção da usina hidrelétrica de Furnas. Com 1.440 km² de superfície, é a maior extensão de água de Minas Gerais. Localizada a cerca de $280 \mathrm{~km}$ de Belo Horizonte e a 480 km de São Paulo, a cidade vem saindo do anonimato. Outros 33 municípios estão nesse mesmo entorno, no entanto, somente Capitólio se destaca com o desenvolvimento da atividade turística. Cânions, cascatas, lagos, cachoeiras, piscinas naturais e outras riquezas vão se incorporando à paisagem, além do forte apelo que se tem na cidade para o esporte radical. Capitólio conta também com vários passeios sobre as montanhas e pontos turísticos nestas áreas. De acordo com a prefeitura local, a atividade turística representa $65 \%$ do produto interno bruto, com mais de 20 hotéis e pousadas, e cerca de 1.500 leitos, além de área de camping e casas para alugar. Com população local em torno de 8.000 habitantes, passa a receber 
4.000 turistas nos finais de semana e 20.000 nos feriados prolongados. 0 objetivo deste estudo é apresentar o desenvolvimento da atividade turística na cidade de Capitólio - Minas Gerais, baseado nos atrativos e opções de lazer existentes. Como metodologia, recorreu-se a fontes bibliográficas de teóricos que tratam sobre desenvolvimento turístico local, atrativos turísticos, esportes radicais, lazer; além de embasamento sobre a caracterização da cidade de Capitólio e do balneário Escarpas do Lago. Realizou-se também uma pesquisa qualitativa, com uma amostragem não probabilística, entrevistando os moradores locais, poder público e iniciativa privada, com intuito de apresentar os atrativos turísticos e opções de lazer existentes na cidade, e como está se organizando para crescer e beneficiar todo o trade turístico.

\section{Palavras-chave}

atividade turística, Capitólio, atrativos, opções de lazer

\section{Introdução}

Nos últimos anos observou-se que o desenvolvimento do turismo e a velocidade a que ele acontece variam de acordo com o potencial que a cidade na qual ele é implantando possui. Mas é certo que elementos como lazer, hospedagem e transporte são indispensáveis para que o turismo exista. Ao longo do tempo diversas definições foram atribuídas ao termo. Conceitualmente, o turismo é traçado como deslocamento, onde envolve infraestruturas básicas, tais como: meios de transporte, de hospedagem, de alimentação, e outros itens que se fazem fundamentais para a satisfação do turista que se direciona a um atrativo ou a uma localidade.

Entende-se, então, que para se ter turismo é necessário ter um tempo livre disponível, fora dos afazeres e obrigatoriedades. Ou seja, é o tempo utilizado pelo indivíduo, da maneira que the for mais conveniente, explorando de si, seus desejos e vontades que muitas vezes são adiados devido à correria do dia a dia e às necessidades de primeira ordem.

Sobre o lazer, é importante uma reflexão pautada na discussão de que é nestes momentos que se tem relaxamento e práticas prazerosas. Compreendendo o destino turístico como o lugar longe do local de moradia, onde os turistas pretendam passar seu tempo, podendo ser uma vila ou vilarejo, uma cidade, uma região, uma ilha ou um país, ou ainda, podendo ser uma única localidade ou um conjunto de destinos, esses devem apresentar atrações turísticas, opções de lazer.

Diante desse fato, localizado no sul do estado de Minas Gerais, o Lago de Furnas compreende uma vasta área que se espraia por $1.406,26 \mathrm{~km}^{2}$. Fruto e consequência de um projeto político nacional desenvolvimentista que objetivava fomentar o crescimento econômico nacional a partir da expansão industrial e de investimentos no setor energético, a formação do lago naquele momento alterou profundamente 
a dinâmica territorial da região, impactando fortemente sobre a economia de Capitólio, foco desta pesquisa.

A cidade de Capitólio com 8.612 habitantes está localizada na mesorregião sul/sudoeste de Minas Gerais, nas proximidades da Serra da Canastra. É um agradabilíssimo polo turístico de Minas Gerais, tem seus atrativos no Lago de Furnas, mais conhecido como o "mar de minas". A maior extensão de água de Minas Gerais é rodeada de enormes lagos. Uma verdadeira praia para quem está a aproximadamente $600 \mathrm{~km}$ do litoral. Foi por causa do Lago de Furnas e de outras atrações de ecoturismo que o Capitólio tornou-se um dos destinos brasileiros mais cobiçados pelos viajantes. A cidade tem belezas naturais como cachoeiras, piscinas naturais e montanhas com trilhas incríveis, possui cânions com mais de $20 \mathrm{~m}$ de altura da represa de furnas, grutas e exuberante vegetação. $O$ objetivo deste estudo é apresentar o desenvolvimento da atividade turística na cidade de Capitólio - Minas Gerais, baseado nos atrativos e opções de lazer existentes.

Indaga-se quais os atrativos turísticos e opções de lazer existentes em Capitólio. Diante dos vários atrativos existentes, este artigo se propôs a tratar somente dos mais visitados por turistas, que são: mirante dos cânions; Cachoeira Diquadinha e Cachoeira Cascatinha; Cachoeira Lagoa Azul; Cascata EcoParque; Paraíso Perdido; Retiro Viking; Trilha do Sol; Cachoeira do Filó e outras cachoeiras; Pedreira Lagoa Azul; passeio de lancha no Lago de Furnas. Além das variadas opções de lazer: os bares flutuantes, os tobogãs com queda no lago, o bar e boate Kanto da Itha, que fica bem ao longo do Lago de Furnas, o mergulho nas piscinas naturais, a pesca esportiva, os passeios em veículos $4 \times 4$, os passeios de helicóptero, de balões, de triciclos, que circulam pelos atrativos apresentados.

Para a construção deste artigo foi desenvolvida uma pesquisa bibliográfica, fundamentanda inicialmente nas temáticas centrais: lazer, turismo, atrativo turístico, planejamento turístico, Capitólio e balneário Escarpas do Lago. Para isso, foi realizado um levantamento bibliográfico que compreendeu textos e publicações (livros, dissertações, teses, periódicos e artigos científicos), bem como outros tipos de trabalhos ou documentos eletrônicos que pudessem ser utilizados como fonte de estudo ou leitura. Realizou-se também uma pesquisa qualitativa, com uma amostragem não probabilística, entrevistando os moradores locais, poder público e iniciativa privada, com intuito de apresentar os atrativos turísticos existentes na cidade, e como está se organizando para crescer e beneficiar todo o trade turístico. Para isso, contou-se com Juracy Melo Rezende, ex-prefeito do município de Capitólio; Abelha, morador de Capitólio; Kênio Rezende, proprietário do KR Passeios Turísticos; e Antônio Carlos da Costa Lopes, proprietário da pousada Serra Verde.

Diante do exposto, este artigo tratará em seu primeiro ponto sobre a introdução; no segundo sobre os aspectos conceituais de tempo livre e lazer; em seu terceiro sobre o turismo e suas dimensões, enfocando seus atrativos turísticos e planejamento; no quarto será abordado o município de Capitólio, sua localização, dados históricos, dados estatísticos, o desenvolvimento da atividade turística e seus atrativos; e, por fim, no quinto, a conclusão. 


\section{Aspectos Conceituais de Tempo Livre e Lazer}

O eixo de estudo do lazer pode ser entendido, após a Revolução Industrial no final do século XVIII e início do XIX na Inglaterra, com o surgimento do chamado "tempo livre", que representa uma conquista da classe operária frente à exploração do capital, e que foi evidenciada, ocorrendo a nítida separação entre tempo-espaço de trabalho (produção) e lazer (atividades contrárias ao trabalho) com atividades que se voltam para a reposição física e mental (Aquino \& Martins, 2018).

Pessoas de diferentes áreas do conhecimento têm buscado o lazer como uma fonte de inspiração para enfrentarem os problemas sociais - seja como uma válvula de escape das dificuldades quotidianas características da sociedade moderna, seja como uma forma pouco habitual de investigar e entender esta mesma sociedade. Percebe-se que cada vez mais há o interesse da população pelo lazer e por espaços e equipamentos que atendam a essa demanda, elevando significativamente a procura dos setores da sociedade que têm buscado se adaptar a essa realidade - como é o caso da indústria do turismo e do lazer que se desenvolve de forma assustadora (Rocha \& Silva, 2002).

Pode-se afirmar que no mundo moderno (globalizado), onde as relações sociais são hegemonicamente voltadas para o capital, o tempo também se transforma numa mercadoria que é apropriada pelos grupos dominantes que determinam as condutas sociais. Nesse sentido, o "tempo livre" ou "tempo disponível" destinado ao lazer passa a ser visto como uma forma de se ganhar dinheiro, acumulando lucros, que alimentam a lógica e a permanência do pensamento centrado no capitalismo industrial (Rocha \& Silva, 2002).

O lazer é entendido como tempo liberado e está compreendido dentro do tempo livre de uma pessoa, tempo este que sobra de um dia, quando se exclui dele o tempo de trabalho, o tempo das necessidades básicas vitais, obrigações sociais e familiares (Camargo, 2017). A chave para a compreensão do conceito de lazer é a ideia de não obrigatoriedade, não imposição de qualquer espécie, pressupondo que o indivíduo tenha ao menos a possibilidade de escolher livremente. Presente na sociedade brasileira, percebe-se que tem uma influência marcante do sociólogo francês Dumazedier (1961/1974), que o define como:

conjunto de ocupações às quais o indivíduo pode entregar-se de livre vontade seja para repousar, seja para divertir-se, recrear-se ou entreter-se ou ainda para desenvolver sua formação desinteressada, sua participação social voluntária, ou sua livre capacidade criadora após livrar-se ou desembaraçar-se das ocupações profissionais, familiares e sociais. (p. 34)

Ao se tratar sobre lazer, entendendo turismo como uma nobre atividade, tem-se a oportunidade de contato, percepção e reflexão sobre pessoas e realidades nas quais estão inseridas por tempo determinado, denominado "espaço urbano democratizado". Os espaços de lazer atraem e acolhem tanto a comunidade, quanto o turista, pois as 
ruas e as praças são construídas para o convívio social e o desenvolvimento de atividades artísticas, físicas, manuais, intelectuais e sociais. Diante do exposto, o turismo deve ser entendido como uma atividade cultural de lazer, bem como uma oportunidade de conhecimento, de enriquecimento da sensibilidade, da percepção social e experiências sugestivas (Marcellino, 2000, como citado em Denardin \& Silva, 2011). É sabido que apesar de espaços urbanos permitirem o convívio e a vivência entre diferentes pessoas e diferentes costumes, as cidades, em sua maioria, não possuem número suficiente de equipamentos concebidos para esta prática.

\section{O Turismo e as Suas Dimensões}

O forte crescimento do turismo na segunda metade do século XX é um ponto marcante no processo modernizador dessa atividade e como fator propulsor do desenvolvimento de determinadas localidades e regiões. É visto que muitos autores consideram que a oferta turística pode proporcionar vantajosas oportunidades, servindo como ferramenta para o combate às desigualdades regionais (Godoy, 2017).

Dessa forma, entende-se o turismo como um fenômeno social, cultural e espacial, que surgiu a partir de uma prática humana; de homens e mulheres que desejaram, movidos pelas mais diversas motivações, experenciar algo diferente do que estavam acostumados a viver em seu cotidiano e em seus locais habituais de residência e convívio social. 0 turismo se configura, portanto, como o encontro de diferentes culturas, como uma atividade que desencadeia uma infinidade de interações de ordem cultural, econômica, social e ambiental entre os sujeitos. (Araújo \& Isayama, 2009, p. 147)

O processo de desenvolvimento do turismo em Capitólio, foco desta pesquisa, tem sua gênese a partir da formação de um bairro às margens do lago no ano de 1978 . 0 poder aquisitivo dos engenheiros e técnicos que chegavam à região nos primeiros anos de funcionamento da usina fomentou a construção do bairro Escarpas do Lago, que foi o primeiro empreendimento para a estruturação do turismo no município e neste vários atrativos foram inseridos para fomentar a atividade turística (Godoy \& Araújo Sobrinho, 2017).

Entende-se por atrativo turístico um local determinado, com características humanas ou naturais específicas, que sejam o foco do visitante e da atenção gerencial (Perace, 1991).

Os atrativos turísticos constituem a oferta turística diferencial de uma determinada região, pois são responsáveis por promover os fluxos turísticos. 0 consumidor escothe o destino que irá visitar em função da experiência turística que esse destino vai the oferecer.

Os atrativos turísticos funcionam como a "mola propulsora" que leva as pessoas a viajarem. Assim, as características dos atrativos naturais e/ou culturais, a qualidade das atividades e experiências oferecidas, a gestão, promoção e comercialização desses empreendimentos são determinantes para o desenvolvimento e nível de competitividade 
do destino (Organização Mundial do Turismo, 2001, como citada em Sancho, 2001). Os atrativos turísticos podem ser classificados em duas categorias: atrativos turísticos naturais e culturais, sendo que o foco desta pesquisa será nos atrativos turísticos naturais.

Atrativos turísticos naturais são constituídos por um conjunto de paisagens, primordiais da natureza, que, por sua beleza, singularidade, atraem pessoas e geram fluxo turístico. São exemplo de atrativos turísticos naturais: montanhas, praias, lagos, pedreiras, cachoeiras, flora, dentre outros (Dias, 2008). Vale ressaltar que os atrativos turísticos são responsáveis por promover o deslocamento de visitantes e impactam na competitividade do destino no mercado turístico. Através de um planejamento turístico ordenado e do controle da capacidade de carga do destino, tem-se a minimização de impactos nos atrativos turísticos existentes em Capitólio, tornando-os mais sustentáveis.

\section{Planejamento Turístico}

Nesse estudo, o turismo aparece como uma atividade ampla e supervalorizada, envolvendo toda a diversidade de atividades, estruturas e facilidades utilizadas quando pessoas deslocam-se, sobretudo, relacionadas ao lazer. 0 planejamento turístico corresponde à preparação dos lugares para receber os fluxos de pessoas em viagem e à instalação da rede de organizações e serviços que comercializarão produtos a esses viajantes (turistas ou não; Dias, 2008).

Para o desenvolvimento sustentável (Hall, 2000/2008) e a vantagem competitiva (Dias, 2008) da atividade turística em um destino, é essencial ter todos os agentes (público, privado e sociedade) envolvidos, de forma participativa e integrada em busca da execução do planejamento turístico, incremento de ações de marketing e inovações. A partir desta premissa, pretende-se mostrar os papéis que devem desempenhar o poder público, a iniciativa privada e a comunidade local em favor do desenvolvimento do turismo em um destino, dando suporte de execução em todas as esferas (sociais, ambientais e econômicas), através da inserção de uma gestão participativa, contínua e sustentável. Para Petrocchi (2001, como citado em Oliveira et al., 2015), as etapas de um planejamento turísticos são:

1.Diagnóstico: é a etapa em que se analisa a situação existente. A qualidade do processo como um todo nasce nesta fase. Um bom diagnóstico é imprescindível para a qualidade de todo o processo.

2.Determinação de objetivos: é a determinação da situação planejada para o futuro. É uma meta a ser atingida. Os objetivos são o ponto de convergência de toda a organização.

3.Estratégias e meio: após análise da situação presente e determinados os objetivos, a etapa seguinte é a escolha das estratégias e a definição dos meios necessários. 
4.Planos de trabalho: são as ações necessárias para que os objetivos sejam alcançados. Situam-se nos planejamentos tático e operacional e observam as estratégias e os meios escolhidos.

5.Controle: fase de acompanhamento do processo e de tomar, quando necessário, atitudes corretivas.

Como citado por Oliveira et al. (2015), para se realizar o planejamento turístico de uma determinada localidade, deve-se realizar um encadeamento lógico dessas etapas de forma que seja compatível com a realidade local, tenha objetivos claros e meios para que as ações sejam realizadas. As ações de planejamento e gestão do turismo no Brasil, no âmbito federal, são responsabilidade do Ministério do Turismo. Atuam também órgãos governamentais estaduais (secretarias e órgãos correlatos), órgãos governamentais municipais (secretarias e departamentos) e de outras instituições (Oliveira et al., 2015).

O setor turístico, a partir da década de 1990, viu-se diante da necessidade de transformar o seu crescimento desenfreado para um novo processo, pautado no desenvolvimento responsável (Beni, 2006, como citado em Fritzen et al., 2015). A proposta foi de uma atividade menos massiva e danosa, e mais organizada, planejada e sustentável, que fez com que o setor se reorganizasse em seus discursos e práticas a nível global, visando o uso racional dos recursos naturais e culturais em uma perspectiva de longo prazo, os quais compreendem a matéria-prima do turismo. Lentamente, o fator economicista da atividade cedeu espaço para a valorização das dimensões social e ecológica, inserindo a questão da sustentabilidade no desenvolvimento do turismo. Se, por um lado, a atividade passou a ser vista como uma promissora alternativa de diversificação produtiva e de forte presença na economia global, capaz de contribuir para o desenvolvimento dos territórios, por outro, as práticas demonstram que nem todos apresentam potencial ou condições para inserção turística (Fritzen et al., 2015).

O planejamento pode desenvolver economicamente lugares, mas deve ser um instrumento pautado em ações dos governos em todos os níveis, dentro de um contexto sustentável e de preservação de recursos. 0 turismo no Lago de Furnas surge como possibilidade para o desenvolvimento dos municípios e da região, fortalecido por meio dos discursos governamentais. No item a seguir, será apresentado o histórico de Capitólio, bem como a contextualização da atividade turística.

\section{Localização de Capitólio e Dados Históricos}

Capitólio é um pequeno município localizado no sudoeste de Minas Gerais, entre a Serra da Canastra e o Lago de Furnas - as duas regiões, quando se encontram, formam algumas das paisagens mais imponentes e lindas do estado e do país, os Cânions de Furnas (Kênio Rezende, entrevista pessoal, 2018). Localizada a cerca de 280 km de Belo Horizonte e a 480 km de São Paulo, a cidade vem saindo do anonimato.

Os cânions são canais, rodeados por paredões, que foram alagados, formando piscinas naturais de águas cristalinas, que fazem parte do imenso lago artificial de águas 
verde-esmeralda que dão forma ao "mar de minas" (Lago de Furnas), o maior espelho d'água do mundo, com mais de $1.000 \mathrm{~km}^{2}$ e quatro vezes maior que até mesmo a Baía de Guanabara, no Rio de Janeiro (Juracy Melo Rezende, entrevista pessoal, 2018). Área alagada artificialmente nos anos de 1963 para a construção da usina hidrelétrica de Furnas, seus $1.440 \mathrm{~km}^{2}$ de superfície são a maior extensão de água de Minas Gerais (Godoy, 2017, p. 71).

Outros 33 municípios estão nesse mesmo entorno, no entanto, somente Capitólio se destaca com o desenvolvimento da atividade turística (Juracy Melo Rezende, entrevista pessoal, 2018).

Antes da criação do Lago de Furnas, em relação à oferta de serviços e à organização industrial, o censo de 1950 descreve que o Capitólio contava com apenas dois estabelecimentos industriais e 23 estabelecimentos comerciais varejistas, dos quais 15 estavam situados na sede, caracterizando a baixa complexidade organizacional do centro urbano naquele momento (Godoy, 2017). Somente no ano de 1975, 12 anos após a constituição do lago, é proposto o primeiro plano de desenvolvimento do Lago de Furnas, elaborado pela empresa norte-americana Tennessee Valley Authority a pedido da Secretaria de Indústria, Comércio e Turismo do estado de Minas Gerais.

O estudo apontou a porção norte do lago como tendo um maior potencial paisagístico a ser explorado, muito em virtude da proximidade com a represa de Furnas e o nível do lago (Secretaria de Indústria, Comércio e Turismo do estado de Minas Gerais, 1975, como citada em Godoy, 2017), região onde se situa Capitólio. Em relação à porção sul do lago, o plano apontava para o potencial dos solos, sendo mais apropriados para o desenvolvimento da agricultura (Secretaria de Indústria, Comércio e Turismo do estado de Minas Gerais, 1975, como citada em Godoy, 2017). Vale ressaltar que o processo de desenvolvimento do turismo em Capitólio tem sua gênese a partir da formação de um bairro às margens do lago no ano de 1978 (Juracy Melo Rezende, entrevista pessoal, 2018). $O$ poder aquisitivo dos engenheiros e técnicos que chegavam à região nos primeiros anos de funcionamento da usina fomentou a construção do bairro Escarpas do Lago, que serviria de base para a estruturação do turismo no município (Antônio Carlos da Costa Lopes, proprietário da pousada Serra Verde, entrevista pessoal, 2018).

\section{Contextualização da Atividade Turística em Capitólio e Dados Estatísticos}

O governo federal firma o pacto federativo de 1988 , fomentando o discurso da busca por atrativos e potencialidades que pudessem viabilizar o orçamento e arrecadação dos municípios e agregar a sua economia local, principalmente, os de pequeno porte, hierarquicamente fragilizados durante o processo de alagamento das áreas produtivas (Godoy, 2017). 0 surgimento do turismo com base no lago começa então a ser esboçado na década de 1990, fortalecido pela articulação dos municípios no apoio ao desenvolvimento dessas atividades, tendo grande influência do discurso do turismo como instrumento para o desenvolvimento local e regional (Kênio Rezende, entrevista pessoal, 2018). 
A exploração da atividade do turismo surge, neste sentido, como potencial gerador de receita para as economias dos pequenos municípios. Na esfera nacional, o Plano Nacional de Turismo (1992) e o Programa Nacional de Municipalização do Turismo (1994) do governo federal exerceram um papel significativo sobre o processo discursivo do turismo como instrumento para o desenvolvimento local e regional (Godoy, 2017). No ano de 1996 foi elaborado um segundo plano para a região do Lago de Furnas, voltado especificamente para o desenvolvimento do turismo com base no lago (Juracy Melo Rezende, entrevista pessoal, 2018).

Realizado a pedido da Secretaria de Estado de Esporte, Lazer e Turismo de Minas Gerais e em parceria com a Associação dos Municípios do Lago de Furnas, o plano fora intitulado de Plano de Desenvolvimento Turístico Integrado Para o Lago de Furnas (Juracy Melo Rezende, entrevista pessoal, 2018). 0 enfoque desse planejamento era fortalecer as bases do turismo no lago. 0 documento apontava que seria necessário investir na promoção do turismo, das potencialidades da região, buscando fomentar e atrair um turismo regional e até mesmo microrregional, servindo de instância de lazer, com áreas de camping, pesca e alojamento nas localidades próximas às rodovias.

O bairro Escarpas do Lago atualmente funciona como balneário, atraindo investimentos imobiliários, como segunda residência em loteamentos de alto padrão nas margens do Lago de Furnas (Abelha, morador da cidade de Capitólio, entrevista pessoal, 2018).

De acordo com a prefeitura local, a atividade turística representa $65 \%$ do produto interno bruto, com mais 74 hotéis e pousadas, e cerca de 1.500 leitos, além de área de camping e casas para alugar. Com população local em torno de 8.612 habitantes, passa a receber 4.000 turistas nos finais de semana e 20.000 nos feriados prolongados. Ainda contam com 316 estabelecimentos de comércio, fora as indústrias que perfazem 80, segundo informação da Econodata (2018).

Outro dado importante é que o município de Capitólio conta hoje com 874 empresas ativas, para atender toda a demanda turística que chega na cidade. Observa-se um crescimento grandioso do município, se comparado com censo realizado em 1950, antes da criação do Lago de Furnas.

\section{Desenvolvimento da Atividade Turística em Capitólio Através de Seus Atrativos}

A região de Capitólio é rica em belezas naturais, mas ressalta-se que as mesmas não se devem somente à ação da natureza. A contribuição humana fez com que grande parte das belezas fossem construídas sobre o Lago de Furnas. Apesar de a desocupação da área do lago ter gerado sérios problemas a milhares de habitantes que residiam no local na época, bem como o alagamento de muitas áreas férteis de produção dos moradores, hoje traz crescimento para economia através do turismo e, é claro, deu origem não só ao Lago de Furnas, como ao incrível cenário dos cânions de Capitólio que atraem turistas de todo Brasil. Diante de entrevistas realizadas com a população local, iniciativa privada e poder público, que formam o tripé da atividade 
do turismo, escreveu-se este artigo, baseado nos retornos adquiridos. Todos os atrativos turísticos existentes e que mais desenvolvem a atividade turística de Capitólio são apresentados a seguir, por Juracy Melo Rezende, ex-prefeito de Capitólio; Abelha, morador de Capitólio; e Kenio Rezende, proprietário de KR Passeios Turísticos.

O primeiro atrativo mais procurado de Capitólio é o mirante dos cânions, já que foi pelas belas fotos do lugar que a região ficou famosa. Do alto do mirante dá para se surpreender ao avistar os enormes paredões de $20 \mathrm{~m}$ de altura e, lá no fundo, a belo Lago de Furnas (Abelha, entrevista pessoal, 2018).

Perto do mirante dos cânions tem-se o segundo atrativo do local que é a Cachoeira Diquadinha e a Cachoeira Cascatinha. Elas ficam a uns $200 \mathrm{~m}$ da entrada do mirante, do outro lado da estrada. As duas cachoeiras possuem várias quedas, formando pequenas piscinas naturais. Por ali também dá para realizar atividades radicais, como trekking, escalada e rapel (Kênio Rezende, entrevista pessoal, 2018).

O terceiro atrativo é a Cachoeira Lagoa Azul, formada por algumas quedas d'água que se transformam em várias piscinas naturais de água cristalina. São vários níveis de cachoeira. Ela está localizada bem próxima à rodovia MG-050 e fica dentro de uma propriedade particular. No sentido Capitólio-Passos, ela fica antes do mirante dos cânions, do lado esquerdo. Na entrada para a cachoeira tem o restaurante Empório Azul e a pousada Lagoa Azul (Antônio Carlos da Costa Lopes, entrevista pessoal, 2018).

O quarto atrativo é a Cascata EcoParque, um dos complexos turísticos mais conhecidos da região: são várias cachoeiras e piscinas naturais que se formam nessa região, que também é área particular. A Cascata EcoParque não é tão extensa quanto os outros parques, tem várias quedas d'águas (Kênio Rezende, entrevista pessoal, 2018).

O quinto atrativo turístico é o Paraíso Perdido, localizado em uma região de cachoeiras no município de São João Batista do Glória, a $40 \mathrm{~km}$ de seu vizinho Capitólio. É uma área privada que funciona como complexo turístico, sendo uma das atrações mais procuradas da região. Por ali encontra-se pelo menos oito cachoeiras e várias piscinas naturais. O lugar é um verdadeiro paraíso. Tem uma área extensa, onde se caminha e sobe por diferentes níveis até chegar à última cachoeira. Para não se perder, basta seguir as marcas - uns pezinhos vermelhos - nas pedras (Kênio Rezende, entrevista pessoal, 2018).

Outro complexo de propriedade privada é o sexto atrativo, denominado Retiro Viking, que parece ter sido aberto para visitação há menos tempo que os demais pontos. Ali a natureza parece ainda mais intacta que nos demais lugares. Com várias quedas d'água em diferentes pontos do parque (Kênio Rezende, entrevista pessoal, 2018).

O sétimo atrativo é a Trilha do Sol, localizada num espaço particular dentro de uma pousada que leva o mesmo nome. A área da Trilha do Sol tem uma estrutura grande de lazer com piscinas e restaurante. Por lá também existe uma área para projetos de pesquisa e estudos sobre o ecossistema do cerrado mineiro. Para conhecer a Trilha do 
Sol, deve-se caminhar uns 800 a $1.200 \mathrm{~m}$ (andando cerca de uns $3 \mathrm{~km}$ no total). Durante essa trilha tem-se várias paradas, sendo as principais: Cachoeira do Poço Dourado, Cachoeira no Limite e Cachoeira do Grito (Kênio Rezende, entrevista pessoal, 2018).

O oitavo atrativo é a Cachoeira do Filó, que parece mais uma praia que cachoeira. A entrada para a área não é sinalizada e não está no mapa oficial de Capitólio. A Cachoeira do Filó está a $38 \mathrm{~km}$ do centro de Capitólio e a $4 \mathrm{~km}$ da usina hidrelétrica de Furnas. 0 acesso é feito pela MG-050. É preciso descer na rodovia e pegar uma trilha curta, porém íngreme, que leva até à cachoeira. 0 solo é basicamente de pedras e tem uma piscina natural cristalina e tipicamente gelada (Kênio Rezende, entrevista pessoal, 2018).

O nono atrativo é o lugar de mais difícil acesso em Capitólio, onde funcionava uma pedreira para exploração e extração de quartzo, que foi desativada. Lá em cima, nas crateras que se formaram, foi surgindo uma "lagoa": enquanto uns dizem ser água de chuva, outros dizem ser decorrente das explosões durante a exploração da pedreira, que fez a água brotar ali. Seja qual for a origem, ficou conhecida como Lagoa Azul. Para chegar, o ideal é por um veículo 4x4 (Kênio Rezende, entrevista pessoal, 2018).

O décimo atrativo é o Lago de Furnas, um dos principais atrativos de Capitólio e mais conhecido como o "mar de minas". Para quem não sabe, o lugar possui o maior número de embarcações de Minas Gerais que circulam na maior extensão de água do estado e é considerado um dos maiores lagos artificiais do mundo (Abelha, entrevista pessoal, 2018). Vale lembrar que os passeios de lancha passam pelo Lago de Furnas e param em algumas opções de lazer que são: os bares flutuantes, os tobogãs com queda no lago, o bar e boate Kanto da Ilha, que fica bem ao longo do Lago de Furnas, o mergulho nas psicinas naturais e a pesca esportiva (Kênio Rezende, entrevista pessoal, 2018). Existem outras opções de lazer para os turistas mais radicais, tais como os passeios em veículos $4 \times 4$, os passeios de helicóptero, de balões, de triciclos, que circulam pelos atrativos apresentados, só que com aventuras nas montanhas ou então aéreas (Kênio Rezende, entrevista pessoal, 2018).

\section{Considerações Finais}

O cenário brasileiro demonstra que o turismo está conquistando espaço junto aos diversos setores da economia, e tem apresentado resultados excepcionais em termos de crescimento econômico. Tem colaborado de forma significativa com a geração de empregos, aumento de renda e geração de divisas, melhorando a qualidade de vida de populações.

Muitos são os exemplos de modelos integrados onde a atividade tornou-se, nalgumas regiões, a melhor alternativa para o desenvolvimento. E Capitólio pode ser um exemplo bem nítido disso. A atividade turística tem a premissa de beneficiar a todos, promovendo o desenvolvimento integrado entre as bases: a comunidade, o setor público e o setor privado. Essa relação propõe ações integradas para o desenvolvimento das localidades e exige certa postura do setor, através de sua rede de relações denominada por Silva (2000) como "rede turística". 
Nas relações comerciais compreendemos a conexão entre várias empresas com propósito mercantil, suas especificidades, seus produtos, sua relação de compra e venda, enfim, seu negócio. A rede turística trata o assunto sobre a perspectiva de uma rede de serviços, observando suas conexões e seu potencial que afirmará sua força econômica para o setor e em Capitólio essa rede é desenvolvida.

Fazendo uma análise comparativa do crescimento do município de Capitólio, antes da criação do Lago de Furnas, observando as falas dos entrevistados, o que se identifica é um comércio pequeno, poucas indústrias, e as pessoas viviam muito da agricultura. Após a criação do Lago de Furnas, inicia-se o discurso de crescimento da região com o desenvolvimento da atividade turística, mas somente 12 anos após é que foi proposto o primeiro plano de desenvolvimento do Lago de Furnas.

Vale ressaltar que o processo de desenvolvimento do turismo em Capitólio tem sua gênese a partir da formação de um bairro nas margens do lago no ano de 1978.0 surgimento do turismo com base no lago começa então a ser esboçado na década de 1990, fortalecido pela articulação dos municípios no apoio ao desenvolvimento dessas atividades, tendo grande influência do discurso do turismo como instrumento para o desenvolvimento local e regional. Inicia-se então o diagnóstico de todos os atrativos naturais existentes, para, a partir de então, planejar ações, de divulgação dos mesmos, para acesso dos visitantes.

Tem-se, neste momento, o inventário da oferta turística apontando os principais atrativos turísticos naturais existentes e a elaboração de propostas de lazer para o município. 0 que se observou nesta pesquisa é que após o desenvolvimento do lago, para fins turísticos, houve um aumento de turistas no município, com interesse em conhecer os atrativos turísticos existente e aproveitar melhor o tempo livre disponível, para fins de lazer.

Este crescimento foi gradativo, e hoje podemos dizer que a atividade turística representa $65 \%$ do produto interno bruto. Houve um crescimento gigantesco no que tange também à qualidade e quantidade dos meios de hospedagem, representando uma média de 74 hotéis e pousadas somente no município, com cerca de 1.500 leitos, além de área de camping e casas para alugar.

Com população local em torno de 8.183 habitantes, passa a receber 4.000 turistas nos finais de semana e 20.000 nos feriados prolongados. Ainda contam com 316 estabelecimentos de comércio, fora as indústrias que perfazem 80. Conclui-se então que as ações do poder público, juntamente com a divulgação dos atrativos naturais existentes no local, bem como as opções de lazer, contribuíram para o crescimento do turismo no município, permitindo a geração de empregos diretos e indiretos, o desenvolvimento da economia, arrecadação de impostos no local, além dos benefícios em toda a infraestrutura de apoio turístico e melhoria da qualidade de vida do morador. 


\section{Referências}

Aquino, C. A. B., \& Martins, J. C. de O. (2018). Ócio, lazer tempo livre na sociedade do consumo e do trabalho. Revista Mal Estar e Subjetividade, 7(2), 479-500. https://periodicos.unifor.br/rmes/article/ view/1595/3577\%3E

Araújo, M., \& Isayama, H. F. (2009). As fronteiras entre lazer e turismo. In H. F. Isayama, L. M. F. Oliveira, T. R. Souza, \& S. R. Silva (Eds.), Coletânea do X Seminário "O Lazer em Debate" (pp. 145 - 150). CELAR; DEF; UFMG.

Camargo, L. O. de L. (2017). 0 que é lazer? Brasiliense.

Denardin, V. C. C., \& Silva, A. P. (2011, 11-12 de novembro). Praças urbanas como espaços para o turismo e lazer um estudo preliminar na Praça General Osóro na cidade de Santa Maria/RS. In II Encontro Semintur Jr. Universidade de Caxias do Sul. https://www.ucs.br/site/midia/arquivos/06_pracas_urbanas. pdf

Dias, R. (2008). Planejamento turístico: Política de desenvolvimento do turismo no Brasil. Atlas.

Dumazedier, J. (1974). Lazer e cultura popular - Debates (M. de L. S. Machado, Trad.). Perspectiva. (Trabalho original publicado em 1961)

Econodata. (2018). Lista de empresas em Capitolio, MG. Retirado em 2018 de https://www.econodata. com.br/lista-empresas/MINAS-GERAIS/CAPITOLIO

Fritzen, F. M., Rudzewicz, L., \& Ceretta, C. C. (2015). Uma proposta de planejamento turístico e sua aplicação em Pelotas, RS. Revista Rosa dos Ventos - Turismo e Hospitalidade, 73), 423-439. http://doi. org/10.18226/21789061.v7iss3p423

Godoy, M. J. (2017). A reestruturação produtiva e territorial nos municipios de pequeno porte do entorno do Lago de Furnas (MG): (Re)funcionalização, transformações e novas dinâmicas [Dissertação de mestrado, Universidade de Brasília]. Repositório Institucional da UNB. https://repositorio.unb.br/handle/10482/24414

Godoy, M. J., \& Araújo Sorinho, F. L. (2017). Os usos múltiplos das águas do lago reservatório de Furnas, Minas Gerais: Turismo, geração de energia elétrica e conflitos. Cenário, 5(8), 128- 147.

Hall, C. M. (2008). Planejamento turístico: Políticas, processos e relacionamentos. Contexto. (Trabalho original publicado em 2000)

Oliveira, C., Minasse, M. H., \& Marques, S. (2015). Processo de formatação de atrativos turísticos sustentáveis. Revista Turismo em Análise, 26(3), 639-667. https://doi.org/10.11606/issn.1984-4867.v26i3p639-667

Sancho, A. (2001). Introdução ao turismo. Roca.

Silva, F. de P. S. da. (2000). Turismo em rede: Uma teia de múltiplas relações. In XXIV Congresso da ABAV. Faculdade de Turismo da Bahia.

Pearce, P. L. (1991). Analyzing tourist attractions. The Journal of Tourism Studies, 1(1), 46-55.

Rocha, L. C., \& Silva, W. A. (2002). Tempo e lazer: Relações com o tempo livre. Revista de Educação Física/UEM, 13(2), 133- 139. 